\title{
A Case of Chronic Intestinal Pseudo-Obstruction
}

\author{
Matt Baichi \\ Thomas Jefferson University
}

Follow this and additional works at: https://jdc.jefferson.edu/tmf

Part of the Gastroenterology Commons

Let us know how access to this document benefits you

\section{Recommended Citation}

Baichi, Matt (2003) "A Case of Chronic Intestinal Pseudo-Obstruction," The Medicine Forum: Vol. 4 , Article 3.

DOI: https://doi.org/10.29046/TMF.004.1.004

Available at: https://jdc.jefferson.edu/tmf/vol4/iss1/3

This Article is brought to you for free and open access by the Jefferson Digital Commons. The Jefferson Digital Commons is a service of Thomas Jefferson University's Center for Teaching and Learning (CTL). The Commons is a showcase for Jefferson books and journals, peer-reviewed scholarly publications, unique historical collections from the University archives, and teaching tools. The Jefferson Digital Commons allows researchers and interested readers anywhere in the world to learn about and keep up to date with Jefferson scholarship. This article has been accepted for inclusion in The Medicine Forum by an authorized administrator of the Jefferson Digital Commons. For more information, please contact: JeffersonDigitalCommons@jefferson.edu. 


\section{A Case Of Chronic Intestinal Pseudo-Obstruction}

Matt Baichi, MD, Resident, Internal Medicine 2000-2003

\section{Introduction}

Scleroderma is a systemic disease characterized by the deposition of excessive collagen and other matrix elements in the skin as well as in multiple internal organs. Scleroderma can be classified into diffuse cutaneous disease and limited cutaneous disease ${ }^{1}$. Limited cutaneous disease is characterized by skin involvement limited to the hands, face, feet, and forearms; it includes the CREST variant (calcinosis, raynauds, esophageal dysmotility, sclerodactyly, and telangiectasia). Diffuse cutaneous disease is characterized by skin involvement as well as early and diffuse visceral involvement. Clinically significant gastrointestinal involvement occurs in approximately $50 \%$ of all patients with scleroderma ${ }^{2}$. The esophagus is the most common site of involvement followed by the ano-rectum, small bowel, colon, and stomach. Several recent reviews of the gastrointestinal manifestations of scleroderma have been written ${ }^{3-5}$. Here, a case of diffuse gastrointestinal scleroderma presenting as chronic intestinal pseudo-obstruction is described.

\section{Case report}

The patient is a 52-year-old female with a 30-year history of GERD, 10-year history of chronic constipation, and a questionable 4-year history of Crohn's disease. The patient was in her usual state of health until three months prior to this admission. At that time, she was hospitalized for nausea and vomiting. Work-up revealed a nonmechanical small bowel obstruction that resolved with conservative management. She was re-hospitalized six times for similar complaints. Each admission revealed non-mechanical small bowel obstruction. Her last admission, however, revealed an ileal stricture, which was subsequently removed. The patient now presents to our hospital with complaints of nausea, bilious emesis, bloating, abdominal distention, increased belching, and decreased appetite. She denies dysphagia, abdominal pain, melena, hematochezia, or diarrhea. She denies history of hepatitis, pancreatitis, or gallbladder disease. Since her first hospitalization three months ago, she has lost 25 pounds. Social history is remarkable for 80 -pack years of tobacco. Family history reveals no gastrointestinal disease. Review of systems is remarkable for persistent parathesias and Raymaud's.
The patient is a moderately cachectic white female. Vital signs are unremarkable except for mild tachycardia. Abdominal exam reveals normal bowel sounds, marked distention, tympanic percussion, soft and non-tender to palpation, without guarding or rebound, and without hernia. Rectal exam reveals external hemorrhoids with brown stool positive for occult blood. Rheumatologic exam reveals mildly thickened and cool fingers, no inflamed joints, normal skin. Neurologic exam reveals normal muscle tone and strength. Blood count is remarkable for white count $14600 / \mathrm{mL}$ with normal differential. Chemistry profile is remarkable for potassium $2.5 \mathrm{Meq} / \mathrm{L}$. Liver profile, amylase, and lipase were within normal limits. ESR 17 seconds, ANA 1:40, speckled. Anticentromere Ab and Anti Scl $70 \mathrm{Ab}$ were negative. Obstruction series showed multiple dilated small bowel loops with relative collapse of the large bowel, air fluid levels within the small bowel, and no intra-peritoneal free air. Pathology of the resected terminal ileum(from previous hospitalization) revealed patchy marked atrophy and fibrosis of the muscularis propria with preferential involvement of the circular layer, vacuolar degeneration of muscle fibers were present, without inflammatory changes of Crohn's Disease. Esophageal manometry revealed lower esophageal sphincter resting pressure in the lower range of normal with aperistalsis of the esophageal body. Small bowel radiographs revealed moderate mega-duodenum with "hide-bound" configuration of mucosal folds throughout the small intestine, but no stricture. Upper endoscopy revealed erosive esophagitis and moderate hiatal hernia. Colonoscopy revealed neoileo-colonic anastamosis that was friable and ulcerated. Biopsy of the anastamosis showed granulation tissue and lamina propria compatible with the anastamotic site.

\section{Diagnosis}

Our patient presented with chronic intestinal pseudoobstruction $^{6-9}$. This is a rare condition characterized by recurrent episodes of intestinal obstruction in the absence of any mechanical defect. Symptoms include nausea, vomiting, abdominal distention, bloating, abdominal pain, and constipation. The differential diagnosis can be divided into myopathic vs neuropathic disorders. Myopathic conditions include infiltrative processes such 
as scleroderma and amyloidosis, familial conditions such as visceral myopathies, and neurologic conditions such as myotonic and other dystrophies. In this case, the history is significant for esophageal dysmotility (longstanding GERD) and Raynaud's phenomenon. Recent ileal biopsy shows patchy atrophy and fibrosis of the muscularis with preferential involvement of the circular layer. These findings are consistent with scleroderma. Histologically, the most significant changes occur in the muscularis layer of bowel. Atrophy and fragmentation of smooth muscle occurs. Initially the atrophy is patchy and later becomes more extensive with associated fibrosis ${ }^{10,11}$. These changes are more pronounced in the circular smooth muscle layer ${ }^{12}$, and atrophy usually exceeds fibrosis ${ }^{13}$. Subsequent small bowel imaging and esophageal manometry confirmed the diagnosis (see discussion).

\section{Discussion}

The esophagus is the most commonly affected organ in the gastrointestinal tract. Normal esophageal manometry shows high amplitude, ordered peristaltic waves and a high resting pressure of the lower esophageal sphincter (LES). On swallowing, the LES relaxes to baseline, and the LES relaxation precedes the arrival of the peristaltic wave. Manometry studies in early scleroderma show increased velocity of the peristaltic wave, discordance of the peristaltic wave with LES relaxation, and failure of the LES to relax to baseline. Later findings include decreased amplitude of peristalsis and low LES resting pressure progressing to aperistalsis in the smooth muscle portion of the esophagus with absent LES resting pressure $^{14,15}$. Gastroesophageal reflux disease (GERD) is the most significant clinical condition. GERD occurs as a result of both the decreased LES resting pressure, which allows an increased number of reflux events, and poor peristalsis, which delays acid clearance ${ }^{16,17}$. The complications of longstanding GERD include candida esophagitis, erosive esophagitis, esophageal stricture, Barret's esophagus, and aspiration. Diagnostic evaluation should therefore include upper endoscopy to rule out complications.
The small intestine is also commonly involved. In the normal small bowel, a cyclical pattern of contractile activity occurs at regular intervals. This is called the migrating myoelectric complex (MMC). The MMC acts as an "intestinal housekeeper" by clearing remnants of digestion and preventing bacterial overgrowth ${ }^{18}$. Patients with scleroderma often lack this MMC. Clinically, chronic intestinal pseudoobstruction and malabsorbtion are seen. Malabsorbtion is the result of bacterial overgrowth ${ }^{19}$. The $\mathrm{H} 2$ breath test is a noninvasive and reliable diagnostic procedure. A nonabsorbable carbohydrate such as lactulose is ingested and a premature rise in exhaled $\mathrm{H} 2$ suggests the presence of intestinal bacteria. The diagnosis of chronic intestinal pseudoobstruction from scleroderma can be made with small bowel barium imaging or biopsy ${ }^{20,21}$. A "hidebound" configuration of the small bowel is a characteristic mucosal fold pattern in which there is a relative decrease in the distance separating the valvulae conniventes. This creates an accordion-like appearance. This finding is uniquely associated with scleroderma. Less common intestinal presentations include pneumatosis cystoides intestinalis, small intestineal telangiectasia, and small bowel diverticula. Prokinetic drugs such as metaclopramide, erythromycin, and octreotide are the treatments of choice.

In the colon, the ano-rectum is commonly affected. Manometry reveals an absent or diminished rectoanal inhibitory reflex ${ }^{22}$. Also, colonic transit is prolonged ${ }^{23}$ and the normal postprandial increase in rectosigmoid motility is $\operatorname{lost}^{24}$. Clinically, fecal incontinence and constipation are the most common presentations. Less common presentations include diarrhea, rectal prolapse, spontaneous perforation, and colonic infarction. Radiographic evaluation of colonic involvement includes barium enema, which may show characteristic "wide mouth", or "fish mouth" diverticula, which are broad based true diverticula caused by the uneven distribution of atrophic muscularis ${ }^{20}$. Treatment includes conservative measures such as increased fluid and fiber intake. Prokinetic agents can be used for improved colonic inertia. 


\section{References}

1. LeRoy EC, Black C, Fleischmajer R, et al. Scleroderma (systemic sclerosis): classification, subsets and pathogenesis (editorial). J Rheumatol 1988;15:202-5.

2. Cohen S, Laufer I, Snape WJ, et al. The gastrointestinal manifestations of scleroderma: Pathogenesis and management. Gastroenterology 1980;79:155-66.

3. Rose S, Young MA, Reynolds JC. Gastrointestinal disorders and systemic disease, part 1. Gastroenterol Clin North Am 1998;27:563-94.

4. Lock G, Holstege A, Lang B, et al. Gastrointestinal manifestations of progressive systemic sclerosis. Am J Gastroenterol 1997;92:763-71.

5. Sjogren RW. Gastrointestinal motility disorders in scleroderma. Arthritis Rheum 1994;37:1265-82.

6. Faulk DL, Anuras S, Christensen J. Chronic intestinal pseudoobstruction. Gastroenterology 1978;74:922-31.

7. Schuffler MD, Rohrmann CA, Chaffee RG, et al. Chronic intestinal pseudoobstruction: a report of 27 cases and review of the literature. Medicine 1981;60:173-96.

8. Schuffler MD. Chronic intestinal pseudo-obstruction syndromes. Med Clin North Am 1981;65:1331-1358.

9. Colemont LJ, Camilleri M. Chronic intestinal pseudoobstruction: diagnosis and treatment. Mayo Clin Proc 1989;64:60-70.

10. Rosson RS, Yesner R. Peroral duodenal biopsy in progressive systemic sclerosis. N Engl J Med 1965;272:391-4.

11. Greenberger NJ, Dobbins WO, Buppert RD. Intestinal atony in progressive systemic sclerosis (scleroderma). Am J Med 1968;45:301-8.

12. Stafford-Brady FJ, Kahn HJ, Ross TM, et al. Advanced scleroderma bowel: complications and management. J Rheumatol 1988;15:869-74.

13. D'Angelo WA, Fries JF, Masi AT, at al. Pathologic observations in systemic sclerosis (scleroderma). Am J Med 1969;46:428-40.

14. Blom-Bulow B, Sundstrom G, Jonson B, et al. Early changes in oesophageal function in progressive systemic sclerosis: a comparison of manometry and radiology. Clin Physiol 1984;4:147-58.
15. Hamel-Roy J, Devroede G, Arhan P, et al. Comparative esophageal and anorectal motility in scleroderma. Gastroenterology 1985;88:1-7.

16. Zamost BJ, Hirschberg J, Ippoliti AF, et al. Esophagitis in scleroderma: prevalence and risk factors. Gastroenterology 1987;92:421-28.

17. Murphy JR, McNally P, Peller P et al. Prolonged clearance is the primary abnormal reflux parameter in patients with progressive systemic sclerosis and esophagitis. Dig Dis Sci 1992;37:833-41.

18. Code CE, Schlegel JF. The gastrointestinal interdigestive housekeeper: motor correlates of the interdigestive myoelectric complex of the dog. Proceedings of the Fourth International Symposium on Gastointestinal Motility, Edited by EE Daniel, K Bowes, JAL Gilbert, B Schofield, TK Schnitka, G Scott. Vancouver, Mitchell Press, 1974.

19. Vantrappen G, Janssens J, Hellemans J, et al. The interdigestive motor complex of normal subjects and patients with bacterial overgrowth of the small intestine. J Clin Invest 1977;59:1158-66.

20. Rohrmann CA, Ricci MT, Krishnamurthy S, et al. Radiologic and histologic differentiation of neuromuscular disorders of the gastrointestinal tract: visceral myopathies, visceral neuropathies, and progressive systemic sclerosis. Am J Roentgenol 1984;143:933-41.

21. Schuffler MD, Beegle RG. Progressive systemic sclerosis of the gastrointestinal tract and hereditary hollow visceral myopathy: Two distinguishable disorders of intestinal smooth muscle. Gastroenterology 1979;77:664-71.

22. Leighton JA, Valdovinos MA, Pemberton JH, et al. Anorectal dysfunction and rectal prolapse in progressive systemic sclerosis. Dis Colon Rectum 1993;36:182-85.

23. Basilisco G, Barbera R, Vanoli M, et al. Delayed colonic transit in constipated patients with progressive systemic sclerosis (PSS). Gastroenterology 1992;102:A421.

24. Battle WM, Snape WJ, Wright S, et al. Abnormal colonic motility in progressive systemic sclerosis. Ann Intern Med 1981;94:749-52. 